\title{
The combined use of Er,Cr:YSGG laser and fluoride to prevent root dentin demineralization
}

\author{
Vinícius Rangel GERALDO-MARTINS ${ }^{1}$, Cesar Penazzo LEPRI ${ }^{1}$, Juliana Jendiroba FARAONI-ROMANO², Regina \\ Guenka PALMA-DIBB²
}

1- Department of Biomaterials, School of Dentistry, Uberaba University, Uberaba, MG, Brazil.

2- Department of Restorative Dentistry, Ribeirão Preto School of Dentistry, University of São Paulo, Ribeirão Preto, SP, Brazil.

\begin{abstract}
Corresponding address: Regina Guenka Palma-Dibb - Departamento de Odontologia Restauradora - Faculdade de Odontologia de Ribeirão Preto Universidade de São Paulo - Av. do Café S/N - Monte Alegre - 14040-904 - Ribeirão Preto - SP - Brazil - Phone/Fax +55 (16) 3602-4016 - e-mail: rgpalma@ forp.usp.br
\end{abstract}

Submitted: October 31, 2013 - Modification: June 27, 2014 - Accepted: July 2, 2014

\section{ABSTRACT}

The use of erbium lasers to prevent caries in enamel has shown positive results. However, it is not known if $\mathrm{Er}$, Cr:YSGG laser can also be used to increase acid resistance of root dentine, which is another dental tissue susceptible to the action of cariogenic bacteria. Objective: To analyze the effects of the Er,Cr:YSGG laser $(\lambda=2.78 \mu \mathrm{m}, 20 \mathrm{~Hz})$ irradiation associated with $2 \%$ neutral sodium fluoride $(\mathrm{NaF})$ to prevent root dentin demineralization. Material and Methods: One hundred human root dentin samples were divided into 10 groups (G) and treated as follows: G1: no treatment; G2: NaF; G3: laser $\left(4.64 \mathrm{~J} / \mathrm{cm}^{2}\right)$ with water cooling $(\mathrm{WC}=5.4 \mathrm{~mL} / \mathrm{min})$; G4: Iaser $\left(4.64 \mathrm{~J} / \mathrm{cm}^{2}\right)$ without WC; G5: laser $(8.92$ $\mathrm{J} / \mathrm{cm}^{2}$ ) with WC; G6: laser $\left(8.92 \mathrm{~J} / \mathrm{cm}^{2}\right)$ without WC; G7: laser $\left(4.64 \mathrm{~J} / \mathrm{cm}^{2}\right)$ with WC and $\mathrm{NaF}$; G8: laser $\left(4.64 \mathrm{~J} / \mathrm{cm}^{2}\right)$ without WC and NaF; G9: laser $\left(8.92 \mathrm{~J} / \mathrm{cm}^{2}\right)$ with WC and $\mathrm{NaF}$; G10: laser $\left(8.92 \mathrm{~J} / \mathrm{cm}^{2}\right)$ without WC and NaF. The NaF gel was applied alone or after 4 min of irradiation. After 14 days of acid challenge, the samples were sectioned and the Knoop microhardness (KHN) test was done at different depths (30,60, 90 and $120 \mu \mathrm{m})$ from the outer dentin surface. Data were analyzed by one-way ANOVA and Fisher's test $(\alpha=5 \%)$. Results: The results showed that G8 and G10 presented higher KHN than the G1 for the depths of 30 and $60 \mu \mathrm{m}$, indicating an increase of the acid resistance of the dentin in up to $35 \%(p<0.05)$. Conclusions: The use of Er,Cr:YSGG laser irradiation at $4.64 \mathrm{~J} /$ $\mathrm{cm}^{2}$ and $8.92 \mathrm{~J} / \mathrm{cm}^{2}$ without water cooling and associated with $2 \% \mathrm{NaF}$ can increase the acid resistance of human root dentin.

Keywords: Lasers. Fluorides. Hardness. Dentin.

\section{INTRODUCTION}

The increase in lifespan associated with the development and application of preventive dentistry concepts have contributed to the maintenance of the teeth in the oral cavity of elderly population. This dental longevity is accompanied by an increasing frequency of exposed root surfaces as a result of periodontal diseases, mechanical injury and/or surgical treatments. When dentin exposition is combined with some situations common to senility, such as reduced salivary flow due to diseases or drugs and the inability to have proper oral hygiene, associated with biofilm accumulation on tooth surfaces, increase the risk of root caries occurrence $^{4}$. Epidemiological studies have shown that the incidence and prevalence of root caries in elders are high. Recent studies pointed out that almost half of the community-dwelling elders had root caries, which indicates the need of preventing this disease in this population?

Since root caries is caused, among other reasons, by a bacterial biofilm that adhere to exposed root surfaces, carious lesions can be prevented or even inactivated through the adoption of preventive actions such as the reduction of carbohydrate intake, biofilm control, oral hygiene instruction and the use of fluoride compounds ${ }^{16}$. Researchers have shown that oral hygiene with fluoride compounds and the incorporation of fluoride 
in public water supply represented important advances in caries prevention ${ }^{21}$. Although the use of fluoride products is considered an important factor to reduce the prevalence of dental caries in both rich and poor countries, it has not led to the elimination of dental caries, which remains an widespread disease affecting all age groups and still represents a risk factor for the occurrence of dental fluorosis if fluoride is used in excess during tooth development ${ }^{20}$. Thus, new techniques and products containing low concentrations of fluoride or not containing fluoride at all, as the high intensity laser irradiation, for example, have been studied in order to prevent the beginning or progression of carious lesions.

The possibility of increasing the acid resistance of dental hard tissues after laser irradiation was first demonstrated in the 1970s, using a $\mathrm{CO}_{2}$ laser $^{24}$. Since then, studies to verify the effects of the interaction between different wavelengths and enamel and dentin were conducted.

The Er,Cr:YSGG (erbium, chromium: yttriumscandium-gallium-garnet) laser works at a wavelength of $2.78 \mu \mathrm{m}$ and it has been investigated for preventive purposes, even though they are usually applied to cavity preparation due to the mechanism of ablation. However, for caries prevention, it is important that the laser does not ablate the treated surface, but change the tissue morphologically or chemically. Therefore, to achieve the preventive effect, studies have been performed with low energy densities (sub-ablative parameters) and without water cooling1,2,9,10,14. It was demonstrated that the irradiation of the enamel surface with an Er,Cr:YSGG laser device, using an energy density of $8 \mathrm{~J} / \mathrm{cm}^{2}$, promotes a sufficient temperature increase to change the chemical structure of enamel, turning it into a less soluble structure ${ }^{9,10}$. Higher fluencies may promote enamel ablation and also induce a greater mineral loss during an acid challenge ${ }^{17}$. Recent studies combined acidulated phosphate fluoride and $\mathrm{Er}, \mathrm{Cr}$ :YSGG laser irradiation, and they found that this association decreased the enamel demineralization more than either fluoride treatment or laser treatment alone $^{9,22}$.

In this way, it is plausible that the association between fluoride and Er,Cr:YSGG laser has been effective in increasing the acid resistance of enamel ${ }^{9,10}$. Thus, it is interesting to know whether these effects also occur in root dentin. A past study performed by Hossain, et al. ${ }^{17}$ (2001) showed that the $\mathrm{Er}, \mathrm{Cr}$ :YSGG increases the acid resistance of dentin. However, the authors concluded that when they were doing cavity preparations on dentin, they used energy densities higher than those used to obtain the preventive effect on the dental tissues ${ }^{17}$. Since the purpose of irradiation for caries prevention is to promote an increase in the tissue surface temperature, only minor morphological or chemical changes must occur. Gao, et al. ${ }^{11}$ (2006) irradiated root dentin samples with a $\mathrm{CO}_{2}$ laser $\left(1.14 \mathrm{~J} / \mathrm{cm}^{2}\right.$ per pulse) combined with $2 \%$ sodium fluoride (NaF) to verify if this treatment was capable to increase the acid resistance of that tissue. The authors concluded that there was a significant synergistic effect of $\mathrm{CO}_{2}$ laser and fluoride treatment combined on the inhibition of root demineralization, possibly due to laser enhanced fluoride uptake in the root dentin $^{11}$. In this manner, there is evidence that lasers can be used to protect root dentin against demineralization.

The aim of this paper was to analyze the effects of $\mathrm{Er}, \mathrm{Cr}$ :YSGG laser irradiation associated with $2 \%$ neutral sodium fluoride ( $\mathrm{NaF}$ ) application on root caries prevention. The null hypothesis is that Er,Cr:YSGG laser irradiation combined with fluoride application do not increase the subsurface microhardness of root dentin after an acid challenge.

\section{MATERIAL AND METHODS}

\section{Experimental design}

The focus of this study was the treatment of root dentin surface using 10 groups of treatment: no treatment (control); $2 \%$ sodium fluoride gel (NaF); Er,Cr:YSGG laser $\left(4.64 \mathrm{~J} / \mathrm{cm}^{2}\right)$ with water cooling $(\mathrm{WC}=5.4 \mathrm{~mL} / \mathrm{min}) ; \mathrm{Er}, \mathrm{Cr}$ :YSGG laser (4.64 $\mathrm{J} / \mathrm{cm}^{2}$ ) without water cooling; Er,Cr:YSGG laser $\left(8.92 \mathrm{~J} / \mathrm{cm}^{2}\right)$ with water cooling; $\mathrm{Er}, \mathrm{Cr}$ :YSGG laser $\left(8.92 \mathrm{~J} / \mathrm{cm}^{2}\right)$ without water cooling; $\mathrm{Er}, \mathrm{Cr}$ :YSGG laser $\left(4.64 \mathrm{~J} / \mathrm{cm}^{2}\right)$ with water cooling and $\mathrm{NaF}$; $\mathrm{Er}, \mathrm{Cr}$ :YSGG laser $\left(4.64 \mathrm{~J} / \mathrm{cm}^{2}\right)$ without water cooling and $\mathrm{NaF}$; $\mathrm{Er}, \mathrm{Cr}$ :YSGG laser $\left(8.92 \mathrm{~J} / \mathrm{cm}^{2}\right)$ with water cooling and NaF; Er,Cr:YSGG laser $\left(8.92 \mathrm{~J} / \mathrm{cm}^{2}\right.$ ) without water cooling and $\mathrm{NaF}$. The experimental units consisted of 100 root dentin blocks from the buccal and lingual surface of human molars. The specimens were randomly assigned to 10 groups $(n=10)$ according to the surface treatment. The quantitative response variable was the dentin longitudinal Knoop microhardness test.

\section{Preparation of the samples}

After the authorization of the Ethical Committee of Ribeirão Preto School of Dentistry, University of São Paulo (CAAE - 0009.0.138.000-09), 100 human molars extracted due to periodontal disease were collected and immediately stored in $0.1 \%$ thymol solution ( $\mathrm{pH}$ 7.0) for less than 30 days. After cleansing and root planning using a curette until dentin exposition, the teeth were stored in distilled water under refrigeration at $4^{\circ} \mathrm{C}$. The crowns were separated from the roots at the cement-enamel junction using a section machine (Minitom, Struers 
Inc., Westlake, OH, USA) with a diamond disk (Isomet; $10.2 \times 0.03 \mathrm{~cm}$, arbor size $1.27 \mathrm{~cm}$, series 15HC diamond; Buehler Ltd., Lake Bluff, IL, USA) in low speed. Then, the roots were sectioned to obtain 100 fragments of $5 \times 5 \times 3 \mathrm{~mm}$ and a $9 \mathrm{~mm}^{2}$ area in the buccal surface in each one of the 100 root dentin samples was delimited. Around this area, two layers of varnish sealer (Colorama Maybelline Ltda, São Paulo, SP, Brazil) were applied.

\section{Experimental groups}

One hundred root dentin samples were randomly divided in 10 groups $(n=10)$. In each sample, the delimitated area was treated according to Table 1. Group 1 received no treatment (control). The samples of group 2 were treated with $2 \% \mathrm{NaF}$ during $4 \mathrm{~min}$ and then stored in a humid environment at $37^{\circ} \mathrm{C}$ until the next step of the experiment.

The samples of the groups 3-10 were irradiated with an Er,Cr:YSGG laser device (WaterLase Millennium $^{\mathrm{TM}}$, Biolase Technologies Inc., San Clemente, CA, USA). This equipment emits photons in a wavelength of $2.78 \mu \mathrm{m}$. The repetition rate was fixed at $20 \mathrm{~Hz}$. The pulse duration was $150 \mu \mathrm{s}$. The beam diameter at the focal area for the handpiece (model 2145) was $600 \mu \mathrm{m}$ (model G4 tip). To ensure consistent spot size with the hand irradiation, an endodontic file was fixed on the top of the handpiece, and kept a distance of $1 \mathrm{~mm}$ from the dentin surface during irradiation. The fluency used for laser irradiation in each group is shown in Table 1. The handpiece was positioned perpendicularly to the root dentin surface, and the samples were irradiated once in each direction, slowly moving the handpiece horizontally and vertically, in order to promote homogeneous irradiation and to cover the entire sample area. The irradiation was performed manually, scanning the dentin surface with a uniform motion during 30 seconds. The output power was measured with a power meter (TM-
744D, Tenmars Electronics Co. Ltd., Taipei, Taiwan). In groups 3, 5, 7 and 9, the water flow was set to $5 \mathrm{~mL} / \mathrm{min}$, which is the minimum amount that the equipment permits. In groups $7-10$, the $2 \% \mathrm{NaF}$ was applied after irradiation during $4 \mathrm{~min}$. At the end of these treatments, all samples were kept in a humid environment at $37^{\circ} \mathrm{C}$. Following, the samples of all groups were submitted to an acid challenge.

\section{Acid challenge}

For the acid challenge, samples were submitted to a $\mathrm{pH}$-cycling procedure, modified from previously described protocols ${ }^{13,14}$. The demineralization solution $(\mathrm{pH}=4.3)$ consisted of $2 \mathrm{mmol} / \mathrm{L}$ of $\mathrm{Ca}$ and $2 \mathrm{mmol} / \mathrm{L}$ of phosphate in buffer solution of acetate $0.075 \mathrm{~mol} / \mathrm{L}$, and the remineralization solution $(\mathrm{pH}=7.0)$ consisted of $1.5 \mathrm{mmol} / \mathrm{L}$ of $\mathrm{Ca}, 0.9 \mathrm{mmol} / \mathrm{L}$ of phosphate and $150 \mathrm{mmol} / \mathrm{L}$ of potassium chloride. First of all, each specimen was immersed in $3 \mathrm{ml}$ of demineralization solution for 6 hours at $37^{\circ} \mathrm{C}$. Then, the specimens were washed with distilled water for 1 minute and immersed in the remineralizing solution for 18 hours at $37^{\circ} \mathrm{C}$. This cycle was carried out for 14 days. At the end of each 5 consecutive days of cycling, the samples were immersed in remineralizing solution for 2 days.

\section{Microhardness test}

At the end of the $\mathrm{pH}$ cycling, the samples were sectioned longitudinally through the exposed area. The samples were embedded in epoxy resin, with the cut face exposed. The exposed surfaces were polished with 600 and 1,200 grit silicon carbide paper (Saint-Gobain Abrasivos Ltda, São Paulo, SP, Brazil) in a polishing machine (MetaServ 250, Buehler Ltd., Lake Bluff, IL, USA) under water cooling followed by $0.3 \mu \mathrm{m}$ alumina paste applied over a felt disc using the same polishing machine. Next, the specimens were ultrasonically cleaned. Subsequently, each sample was assessed with the

Table 1- Irradiation parameters of the experimental groups

\begin{tabular}{|c|c|c|c|c|c|}
\hline \multirow[t]{2}{*}{ Group } & Treatment & Power & Energy & Repetition & Water \\
\hline & & Output (W) & Density $\left(\mathrm{J} / \mathrm{cm}^{2}\right)$ & Rate $(\mathrm{Hz})$ & Cooling (mL/min) \\
\hline 1 & None & --- & --- & --- & --- \\
\hline 2 & $2 \% \mathrm{NaF}$ & --- & --- & --- & --- \\
\hline 3 & Laser & 0.25 & 4.64 & 20 & 5.4 \\
\hline 4 & Laser & 0.25 & 4.64 & 20 & 0 \\
\hline 5 & Laser & 0.50 & 8.92 & 20 & 5.4 \\
\hline 6 & Laser & 0.50 & 8.92 & 20 & 0 \\
\hline 7 & Laser+2\% NaF & 0.25 & 4.64 & 20 & 5.4 \\
\hline 8 & Laser+2\% NaF & 0.25 & 4.64 & 20 & 0 \\
\hline 9 & Laser+2\% NaF & 0.50 & 8.92 & 20 & 5.4 \\
\hline 10 & Laser+2\% NaF & 0.50 & 8.92 & 20 & 0 \\
\hline
\end{tabular}


Table 2- Knoop microhardness numbers ( \pm the standard deviations) found at different depths for all groups after the acid challenge. Different superscripted letters in the columns mean statistically significant differences $(p<0.05)$

\begin{tabular}{ccccc}
\hline Groups & \multicolumn{5}{c}{ Depth } \\
\hline 1 & $\mathbf{3 0 \mu \mathrm { m }}$ & $\mathbf{6 0 \mu \mathrm { m }}$ & $\mathbf{9 0} \boldsymbol{\mu m}$ & $\mathbf{1 2 0} \boldsymbol{\mu m}$ \\
\hline 2 & $27.32(4.76)^{\mathrm{a}}$ & $30.12(5.51)^{\mathrm{c}}$ & $36.59(6.04)^{\mathrm{e}}$ & $36.2(6.76)^{\mathrm{f}}$ \\
3 & $33.55(7.87)^{\mathrm{ab}}$ & $36.81(9.2)^{\mathrm{cd}}$ & $38.91(7.04)^{\mathrm{e}}$ & $41.13(6.62)^{\mathrm{f}}$ \\
4 & $30.38(4.26)^{\mathrm{ab}}$ & $32.24(4.25)^{\mathrm{cd}}$ & $36.27(4.88)^{\mathrm{e}}$ & $39.73(5.55)^{\mathrm{f}}$ \\
\hline 5 & $31.49(6.56)^{\mathrm{ab}}$ & $35.72(7.10)^{\mathrm{cd}}$ & $39.16(8.89)^{\mathrm{e}}$ & $41.63(7.69)^{\mathrm{f}}$ \\
\hline 6 & $31.91(3.88)^{\mathrm{ab}}$ & $36.32(6.11)^{\mathrm{cd}}$ & $39.57(6.29)^{\mathrm{e}}$ & $42.8(5.76)^{\mathrm{f}}$ \\
7 & $33.84(5.62)^{\mathrm{ab}}$ & $38.11(6.06)^{\mathrm{cd}}$ & $41.52(5.74)^{\mathrm{e}}$ & $44.66(5.64)^{\mathrm{f}}$ \\
\hline 8 & $30.94(3.82)^{\mathrm{ab}}$ & $34.81(3.59)^{\mathrm{cd}}$ & $36.56(4.56)^{\mathrm{e}}$ & $39.45(5.00)^{\mathrm{f}}$ \\
\hline 9 & $36.74(5.64)^{\mathrm{b}}$ & $42.98(4.51)^{\mathrm{d}}$ & $44.87(5.53)^{\mathrm{e}}$ & $47.7(5.55)^{\mathrm{f}}$ \\
\hline & $35.34(6.29)^{\mathrm{ab}}$ & $39.85(6.74)^{\mathrm{cd}}$ & $41.9(5.91)^{\mathrm{e}}$ & $44.89(5.26)^{\mathrm{f}}$ \\
\hline
\end{tabular}

Knoop microhardness examination of the dentin, starting at $30 \mu \mathrm{m}$ from the outer surface, with indents at $30 \mu \mathrm{m}$ intervals between $30 \mu \mathrm{m}$ and $120 \mu \mathrm{m}$ from the anatomical surface. In each area, three measurements of Knoop microhardness were done, and the distance between measurements was of $500 \mu \mathrm{m}$ to prevent the marks from overlapping each other. A static load of $10 \mathrm{~g} / 15 \mathrm{~s}$ was applied.

\section{Statistical analysis}

First, the assumptions of equality of variances (modified Levene's test) and the normality of the error distributions (Shapiro-Wilk test) were checked for the response variables tested. Since the assumptions were satisfied, the one-way ANOVA test $(a=5 \%)$ was applied using OriginPro 8 SRO software (Origin Lab Corporation, Northampton, MA, USA). Fisher's test was used at the 5\% significance level to evaluate the differences among means.

\section{RESULTS}

Table 2 shows the KNH for all groups. Statistical analysis compared treatments at each depth, and no comparisons were made among depths. At $30 \mu \mathrm{m}$, groups 8 ( $0.25 \mathrm{~W}+2 \% \mathrm{NaF}$ without water cooling) and 10 ( $0.5 \mathrm{~W}+2 \% \mathrm{NaF}$ without water cooling) showed a surface more resistant to acids than group 1 (control) $(p<0.05)$. The data found in the other experimental groups were not different from the $\mathrm{KHN}$ found for group 1 . At $60 \mu \mathrm{m}$, groups 8 and 10 also showed higher KHN than group $1(p<0.05)$. The results found in control group were similar to those found in the other experimental groups. At 90 and $120 \mu \mathrm{m}$, no statistically differences were found among all groups.

\section{DISCUSSION}

While the combination of fluoride and Er,Cr:YSGG laser has been studied to inhibit enamel demineralization, there is a lack of investigation on the use of that method on root dentin to increase acid resistance. The present study assessed the use of laser and $2 \% \mathrm{NaF}$, combined or individually, to increase the acid resistance of root dentin surface. The null hypothesis of the present study was rejected, since the results showed that the samples irradiated with $0.25 \mathrm{~W}$ and $0.50 \mathrm{~W}$ without water cooling, followed by $2 \% \mathrm{NaF}$ application, presented surfaces more resistant to acids when compared to untreated samples. This situation occurred for the depths of 30 and $60 \mu \mathrm{m}$.

The data found for the depths of 90 and 120 $\mu \mathrm{m}$ were not statistically different. This probably occurred because of the short period used for the acid challenge, which did not allowed the penetration of the demineralizing solution through the deeper layers of root dentin (90 and $120 \mu \mathrm{m}$ ). For this reason, the dentin layers deeper than 120 $\mu \mathrm{m}$ were not analyzed. Thus, further studies should be conducted using a longer period of acid challenge to know if these deeper layers of dentin would be affected by the acid challenge.

The use of fluoride to prevent root surfaces caries had already been demonstrated. Previous studies suggested that the treatment and prevention of root caries should involve an extra fluoride regimen in addition to regular daily fluoride dentifrice use $23,25,26$. Additionally, a previous in vitro study showed that the combination of acidulated phosphate fluoride (APF) application and 1100-ppm-F dentifrice used 3 times a day provided a synergistic effect, enhancing the availability of fluoride in biofilm fluid and reducing root dentin demineralization ${ }^{25}$.

Those studies suggested that only the use of 
fluoride gel is not able to protect the root surface against the attack of acidogenic bacteria. In fact, the results of the present study suggested that the association between the Er,Cr:YSGG laser irradiation and fluoride seemed to promote a surface more resistant to acids than the simple application of NaF. Furthermore, laser and fluoride treatments applied individually resulted in comparable and low levels of root caries inhibition. When Er,Cr:YSGG laser was combined with fluoride treatment, we achieved about $35 \%$ of root dentin demineralization reduction when comparing to the control group.

The mechanism of the synergistic effect of Er,Cr:YSGG laser irradiation followed by fluoride application is still unknown. It was reported that laser treatment significantly increase fluoride uptake by $400 \%$ and $37 \%$ in loosely and firmly bound forms, respectively ${ }^{11}$. During a cariogenic challenge, the loosely bound calcium fluoride $\left(\mathrm{CaF}_{2}\right)$ may liberate the fluoride ions to inhibit demineralization and enhance remineralization. The firmly bound fluoride integrated into the crystalline structure may increase crystal stability and acid resistance. A study has revealed a contraction in the a-axis dimension and an improvement in the enamel crystallinity induced by laser irradiation, with a further reduction of the axis of hydroxyapatite crystals caused by the combined laser-fluoride treatment ${ }^{6}$. Probably some of those effects also occur in dentin. In addition, the firmly bound fluoride may serve as a fluoride reservoir, with a greater substantivity than that of the loosely bound fluoride $^{11}$. In this way, these factors may be the main reasons for the increase of the acid resistance of root dentin.

It is important to note that, in the present study, $2 \% \mathrm{NaF}$ was applied after irradiation to observe whether the irradiated dentin surface enhances the retention of fluoride ions. In fact, that synergistic effect could be observed on samples irradiated without water cooling.

Regarding the energy densities used, although there were no statistically significant differences among the treated groups, the higher parameters seemed to promote better results than the lower ones when only the laser was used. There were no previous research that used the Er,Cr:YSGG laser for root caries prevention, so the parameters used in this study were based on those used for the enamel irradiation with the same wavelength. Previous studies showed that enamel irradiation with an energy density of $8 \mathrm{~J} / \mathrm{cm}^{2}$ was necessary to promote a temperature increase sufficiently high to modify the chemical structure of the enamel, turning it into a less soluble structure ${ }^{8,10,22}$. Lower energy densities should not be able to increase the temperature of the surface up to $300-450^{\circ} \mathrm{C}$, and, consequently, less soluble compounds would not be formed ${ }^{8}$.

Another hypothesis suggested the "organic blocking" theory, when the partial denaturation of the organic matrix caused by laser irradiation may block the diffusion pathway in enamel, resulting in a retardation of enamel demineralization ${ }^{19}$. Blocking the diffusion pathway may affect the porosity of the enamel and the microsurface area. The organic matter, causing a statistically significant decrease in the pore volume and surface area in enamel after laser irradiation, may be one of the key players in the laser induced blocking of diffusion pathway and subsequent prevention of enamel demineralization ${ }^{11,27}$.

As shown previously ${ }^{3}$, the laser Er,Cr:YSGG also produces the sealing of dentinal tubules through melting and resolidification of the dentin, which reduces the permeability of that tissue and thus hinders the penetration of the acid into the deeper layers of dentin.

These theories support the results obtained in the present study. The absence of water cooling may lead to an increase in the temperature of the surface, promoting the same effects that occur in enamel, as described before, and this also can be observed here when groups that used the same energy density are individually compared. The possibility of using minimum levels of water (5.0 $\mathrm{mL} / \mathrm{min}$ ) during irradiation was thought to avoid thermal damages in the tissue. The researchers are aware that the presence of large amounts of water hinders the preventive effect promoted by Er,Cr:YSGG. Somehow, the presence of water was more disadvantageous when used with lower parameters, as evidenced by the results obtained in groups 3 and 7 .

A previous study showed that the dentin surface, irradiated with a fluency of $4.64 \mathrm{~J} / \mathrm{cm}^{2}$ and with the same $\mathrm{Er}, \mathrm{Cr}$ :YSGG device under water cooling (15.0 $\mathrm{mL} / \mathrm{min})$, presented opened dentinal tubules ${ }^{12}$. Although the amount of water used by these authors was almost three times higher than that used here, this finding suggests that the presence of water cooling does not made easier for the laser to promote the preventive effect in the root dentin, since opened dentinal tubules facilitate the acid penetration, causing the carious lesions extend more into the dentin ${ }^{5}$. Conversely, when water cooling is not used, the dentin undergoes a melting process that involves, among other things, the obliteration of the dentinal tubules ${ }^{3}$. This hinders the penetration of acids into the dentin, making this tissue more resistant to demineralization. This hypothesis explains why the results obtained in the absence of cooling were a little bit better even for the same energy density.

In the present study, few small brown spots were observed on the root dentin when the 
energy density of $8.92 \mathrm{~J} / \mathrm{cm}^{2}$ was used without water cooling. That finding suggests that some areas of root dentin overheated. That factor is of extreme importance because it indicates that higher fluencies than that used here would cause significant thermal damage in irradiated dentin ${ }^{15,18}$. Furthermore, higher fluencies could lead to dentin ablation and also induce a greater mineral loss during an acid challenge ${ }^{17}$.

Therefore, analyzing the results obtained in the present study, it was possible to verify, after the Knoop microhardness test, that the use of $\mathrm{Er}, \mathrm{Cr}$ :YSGG laser associated with $2 \% \mathrm{NaF}$ application promoted an increase in the acid resistance of the human root dentin in up to $35 \%$. However, laser irradiation without water cooling promoted thermal damage on dentin. On the other hand, the presence of water, even in small amounts, did not favor the preventive effect of the $\mathrm{Er}, \mathrm{Cr}$ :YSGG laser irradiation. Further studies using lower energy densities and lasers with different wavelengths are needed, not only to confirm the synergistic effect between laser and fluoride, but also to understand what actually happens in the irradiated tissue that makes it more resistant to acids.

\section{CONCLUSIONS}

Considering the limitations of the present study, it can be concluded that the association between laser and fluoride can increase the acid resistance of human root dentin if that irradiation is provided without water cooling.

\section{REFERENCES}

1- Apel C, Birker L, Meister J, Weiss C, Gutknecht N. The cariespreventive potential of subablative Er:YAG and Er:YSGG laser radiation in an intraoral model: a pilot study. Photomed Laser Surg. 2004;22:312-7.

2- Apel C, Meister J, Götz H, Duschner H, Gutknecht N. Structural changes in human dental enamel after subablative erbium laser irradiation and its potential use for caries prevention. Caries Res. 2005;39:65-70.

3- Aranha AC, Eduardo CP. In vitro effects of Er,Cr:YSGG laser on dentine hypersensitivity. Dentine permeability and scanning electron microscopy analysis. Lasers Med Sci. 2012;27:827-34. 4- Bahrami G, Vaeth M, Kirkevang LL, Wenzel A, Isidor F. Risk factors for tooth loss in an adult population: a radiographic study. J Clin Periodontol. 2008;35:1059-65.

5- Cummins D. Dentin hypersensitivity: from diagnosis to a breakthrough therapy for everyday sensitivity relief. J Clin Dent. 2009;20:1-9.

6- Deng Y, Hsu CY. Combined effect of fluoride and laser on the crystalline structure of human enamel: a pilot study. Proc SPIE. 2005;5687:42-9.

7- Du M, Jiang H, Tai B, Zhou Y, Wu B, Bian Z. Root caries patterns and risk factors of middle-aged and elderly people in China. Community Dent Oral Epidemiol. 2009;37:260-6.
8- Fowler BO, Kuroda S. Changes in heated and in laser-irradiated human tooth enamel and their probable effects on solubility. Calcif Tissue Int. 1986;38:197-208.

9- Freitas PM, Rapozo-Hilo M, Eduardo CP, Featherstone JD. In vitro evaluation of erbium,chromium:yttrium-scandium-galliumgarnet laser-treated enamel demineralization. Lasers Med Sci. 2010;25:165-70.

10- Fried D, Featherstone JDB, Visuri SR, Seka W, Walsh JT. The caries inhibition potential of Er:YAG and Er:YSGG laser radiation. Proc SPIE. 1996;2672:73-8.

11- Gao XL, Pan JS, Hsu CY. Laser-fluoride effect on root demineralization. J Dent Res. 2006;85:919-23.

12- Geraldo-Martins VR, Armas-Vega AC, Marques MM. Influence of etching with $\mathrm{Er}, \mathrm{Cr}$ :YSGG laser on the microtensile bond strength of adhesives to dentin. J Oral Lasers Appl. 2010;10:79-86.

13- Geraldo-Martins VR, Lepri CP, Palma-Dibb RG. Effect of different root caries treatments on the sealing ability of conventional glass ionomer cement restorations. Lasers Med Sci. 2012;27:39-45.

14- Geraldo-Martins VR, Lepri CP, Palma-Dibb RG. Influence of $\mathrm{Er}, \mathrm{Cr}$ :YSGG laser irradiation on enamel caries prevention. Lasers Med Sci. 2013;28(1):33-9.

15- Geraldo-Martins VR, Tanji EY, Wetter NU, Nogueira RD, Eduardo CP. Intrapulpal temperature during preparation with the Er:YAG laser: an in vitro study. Photomed Laser Surg. 2005;23:182-6.

16- Griffin SO, Regnier E, Griffin PM, Huntley V. Effectiveness of fluoride in preventing caries in adults. J Dent Res. 2007;86:410-5. 17- Hossain M, Kimura Y, Nakamura Y, Yamada Y, Kinoshita JI, Matsumoto $\mathrm{K}$. A study on acquired acid resistance of enamel and dentin irradiated by Er,Cr:YSGG laser. J Clin Laser Med Surg. 2001;19:159-63.

18- Hossain M, Nakamura Y, Yamada Y, Kimura Y, Matsumoto N, Matsumoto $\mathrm{K}$. Effects of $\mathrm{Er}, \mathrm{Cr}$ :YSGG laser irradiation in human enamel and dentin: ablation and morphological studies. J Clin Laser Med Surg. 1999;17:155-9.

19- Hsu CY, Jordan TH, Dederich DN, Wefel JS. Effects of lowenergy $\mathrm{CO}_{2}$ laser irradiation and the organic matrix on inhibition of enamel demineralization. J Dent Res. 2000;79:1725-30.

20- Ismail AI, Hasson H. Fluoride supplements, dental caries and fluorosis: a systematic review. J Am Dent Assoc. 2008;139:145768.

21- Meenakshi, Maheshwari RC. Fluoride in drinking water and its removal. J Hazard Mater. 2006;137:456-63.

22- Moslemi M, Fekrazad R, Tadayon N, Ghorbani M, Torabzadeh $H$, Shadkar MM. Effects of Er,Cr:YSGG laser irradiation and fluoride treatment on acid resistance of the enamel. Pediatr Dent. 2009;31:409-13.

23- Paraskevas S, Danser MM, Timmerman MF, van der Velden $U$, van der Weijden GA. Amine fluoride/stannous fluoride and incidence of root caries in periodontal maintenance patients. A 2 year evaluation. J Clin Periodontol. 2004;31:965-71.

24- Stern RH, Vahl J, Sognnaes RF. Laser enamel: ultrastructural observations of pulsed carbon dioxide laser effects. J Dent Res. 1972; 51:455-60.

25- Vale GC, Tabchoury CP, Del Bel Cury AA, Tenuta LM, ten Cate JM, Cury JA. APF and dentifrice effect on root dentin demineralization and biofilm. J Dent Res. 2011;90:77-81.

26- Wallace MC, Retief DH, Bradley EL. The 48-month increment of root caries in an urban population of older adults participating in a preventive dental program. J Public Health Dent. 1993;53:133-7. 27- Ying D, Chuah GK, Hsu CY. Effect of Er:YAG laser and organic matrix on porosity changes in human enamel. J Dent. 2004;32:41-6. 